\title{
Next generation sequencing with copy number variant detection expands the phenotypic spectrum of HSD17B4-deficiency
}

\author{
Daniel S Lieber ${ }^{1,2,3,4 \dagger}$, Steven G Hershman ${ }^{1,2,3,4 \dagger}$, Nancy G Slate ${ }^{1,2}$, Sarah E Calvo ${ }^{1,2,3,4}$, Katherine B Sims ${ }^{2,5}$,
} Jeremy D Schmahmann ${ }^{6^{*}}$ and Vamsi K Mootha $a^{1,2,3,4,7^{*}}$

\begin{abstract}
Background: D-bifunctional protein deficiency, caused by recessive mutations in HSD17B4, is a severe, infantile-onset disorder of peroxisomal fatty acid oxidation. Few affected patients survive past two years of age. Compound heterozygous mutations in HSD17B4 have also been reported in two sisters diagnosed with Perrault syndrome (MIM \# 233400), who presented in adolescence with ovarian dysgenesis, hearing loss, and ataxia.

Case presentation: An adult male presented with cerebellar ataxia, peripheral neuropathy, hearing loss, and azoospermia. The clinical presentation, in combination with biochemical findings in serum, urine, and muscle biopsy, suggested a mitochondrial disorder. Commercial genetic testing of 18 ataxia and mitochondrial disease genes was negative. Targeted exome sequencing followed by analysis of single nucleotide variants and small insertions/deletions failed to reveal a genetic basis of disease. Application of a computational algorithm to infer copy number variants (CNVs) from exome data revealed a heterozygous $12 \mathrm{~kb}$ deletion of exons 10-13 of HSD17B4 that was compounded with a rare missense variant (p.A196V) at a highly conserved residue. Retrospective review of patient records revealed mildly elevated ratios of pristanic:phytanic acid and arachidonic:docosahexaenoic acid, consistent with dysfunctional peroxisomal fatty acid oxidation.

Conclusion: Our case expands the phenotypic spectrum of HSD17B4-deficiency, representing the first male case reported with infertility. Furthermore, it points to crosstalk between mitochondria and peroxisomes in HSD17B4-deficiency and Perrault syndrome.
\end{abstract}

Keywords: HSD17B4, DBP, D-bifunctional protein deficiency, Perrault syndrome, Next-generation sequencing, Exome sequencing, Copy number variants, CNV, Mitochondria, Mitochondrial disorders, Mitochondrial disease, Mendelian disorders, Human genetics, Ataxia, Multi-system disorders, Peroxisomal defects

\section{Background}

Patients with mitochondrial disorders can present with cerebellar ataxia, often in combination with other neurological and non-neurological symptoms [1]. Such disorders can be caused by mutations in the mitochondrial DNA or by recessive, dominant, or X-linked mutations

\footnotetext{
* Correspondence: jschmahmann@partners.org; vamsi@hms.harvard.edu †Equal contributors

${ }^{6}$ Ataxia Unit, Cognitive Behavioral Neurology Unit, Laboratory for

Neuroanatomy and Cerebellar Neurobiology, Department of Neurology,

Massachusetts General Hospital \& Harvard Medical School, Boston, MA 02114,

USA

${ }^{1}$ Howard Hughes Medical Institute and Department of Molecular Biology,

Massachusetts General Hospital, Boston, MA 02114, USA

Full list of author information is available at the end of the article
}

in nuclear-encoded genes essential to mitochondrial respiratory chain function [2]. Due to genetic and phenotypic heterogeneity, single gene testing is often ineffective and targeted exome sequencing is emerging as an efficient alternative [3]. Here, we report the application of such technology to a perplexing case of progressive, cerebellar ataxia in whom traditional single gene testing did not yield a molecular diagnosis.

\section{Case presentation}

A 35-year-old man presented for evaluation of a gait disorder progressing since childhood, cognitive impairment, and sensorineural hearing loss. He had mildly delayed 
developmental milestones. Progressive ataxia necessitated a cane by age 18, wheelchair-dependence by 29 . He needed assistance academically through school, and graduated from college at age 26. Sensorineural hearing loss was noted at age 34. Review of medical charts revealed documented azoospermia. He was the product of neurologically healthy, non-consanguineous parents, with one healthy, fertile sister.

Neurological examination revealed high arched feet, hammer toes, and normal secondary sexual characteristics. Oculomotor examination showed square wave jerks at rest, gaze-evoked nystagmus, saccadic intrusions into pursuit, hypermetric saccades, and failure to suppress the vestibular ocular reflex. There was mild dysarthria, moderate upper and lower extremity dysmetria, and moderate gait ataxia (Brief Ataxia Rating Scale: 13/30). Deep tendon reflexes were normal in the arms, exaggerated in the legs. Plantar responses were flexor. He had impaired pin sense in the feet. Hearing was intact on office testing. He had an average IQ (FSIQ $=98,45$ th percentile, WAIS-III), bland affect, reduced visual motor processing speed, and was impaired on a card-sorting task, a nonverbal test of concept formation and cognitive flexibility, with perseverative errors and trouble maintaining set.

Brain MRI from age 14 through 35 showed progressive cerebellar volume loss (Figure 1). Nerve conduction studies revealed absent long latency responses in the legs, symmetrically reduced motor conduction velocities in arms and legs with normal amplitudes; needle examination was normal. Waking electroencephalogram was normal. Audiology testing revealed mild decrease in hearing for higher frequencies bilaterally, decreased speech intelligibility, and word recognition $86 \%$ on the right, and $94 \%$ on the left.

Laboratory data included normal routine tests and negative genetic tests for 18 mitochondrial or ataxia genes (See Additional file 1). Testosterone was low at $164 \mathrm{ng} / \mathrm{dL}(270-1100)$ and follicle-stimulating hormone (FSH) was elevated at $15 \mathrm{mIU} / \mathrm{mL}$ (1-8). Plasma lactate was within normal limits, while pyruvate was essentially normal at $0.18 \mathrm{mmol} / \mathrm{L}(0.08-0.16)$. Urine organic acid

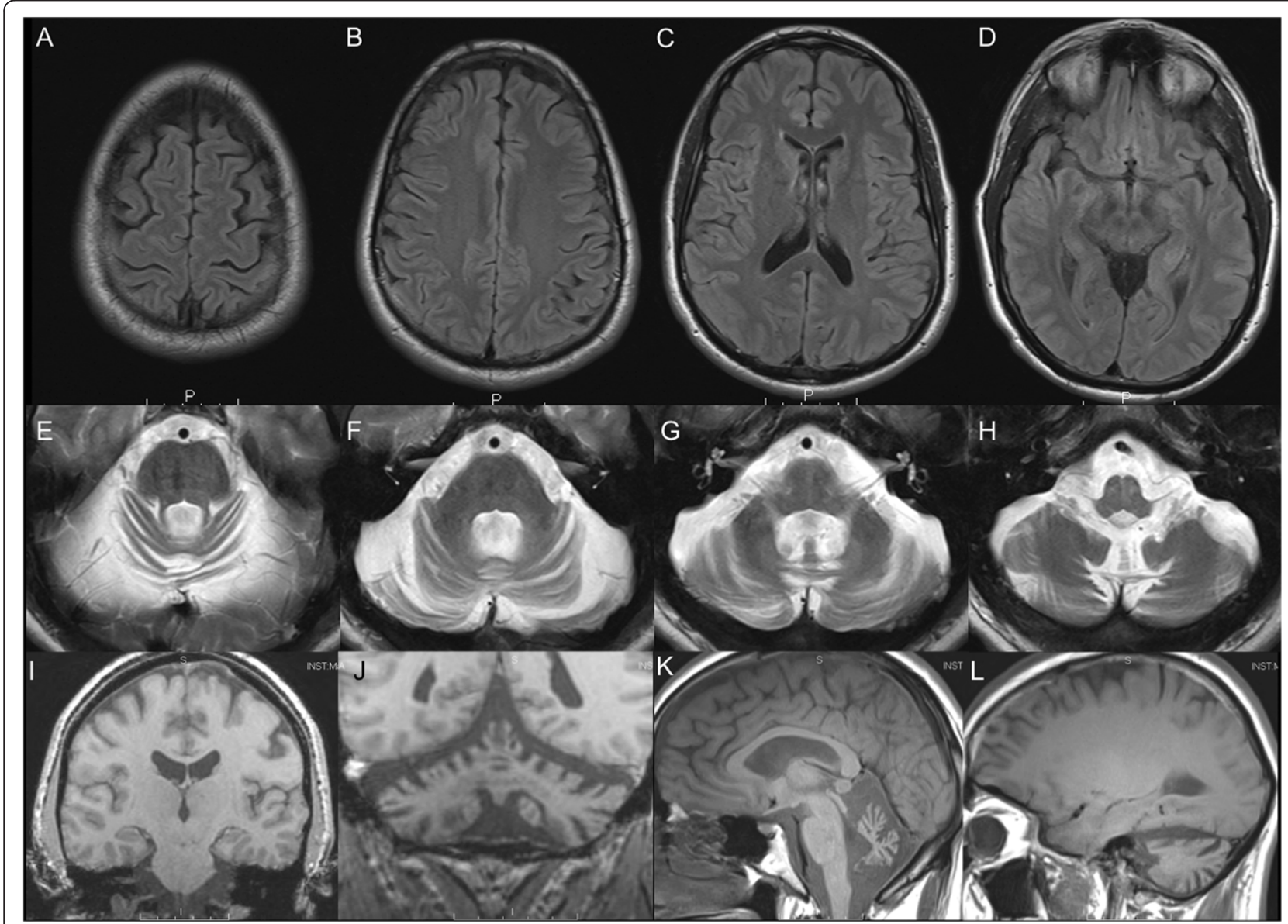

Figure $1 \mathrm{MRI}$ at age 35 demonstrating cerebellar volume loss with preservation of cerebral hemispheres. A-D) FLAIR axial; E-H) T2 axial; I-J) Coronal T1; K-L) Sagittal T1. 
analysis showed small amounts of lactate in urine. Tests of long and very long chain fatty acids revealed elevated total plasma $\omega-9$ fatty acids $(500 \mathrm{ug} / \mathrm{mL}$ or $24.07 \%$ of total fatty acids; reference range: $15.4 \%-22.0 \%)$. The per-

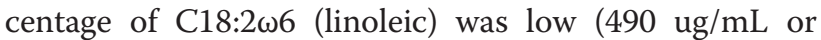
$23.6 \%$ of total; range: $24.2 \%-33.8 \%$ ), and the ratio of pristanic acid/phytanic acid (0.19; range: 0.01-0.18), percentage of arachidonic acid $(208 \mathrm{ug} / \mathrm{mL}$ or $10.0 \%$ of total; range: $4.0 \%-9.5 \%$ ), and ratio of arachidonic/docosaehexenoic acid (5.6; range: 0.43-5.4) were mildly elevated.

Muscle biopsy appeared unremarkable on light and electron microscopy. Muscle coenzyme Q10, free and total carnitine, and acylcarnitine were normal, but electron transport chain testing of a skeletal muscle biopsy (Additional file 1) revealed mild Complex I deficiency (22\% Complex I + III after normalization to citrate synthase).

\section{Results}

Given the clinical suspicion of mitochondrial disease, we performed targeted exome sequencing as previously described, interrogating the entire mitochondrial DNA (mtDNA) and the exons of 1598 nuclear genes implicated in mitochondrial disease, mitochondrial function, or other disorders with phenotypic overlap [3]. We identified 1,569 single nucleotide variants (SNVs) and small insertions/deletions (indels) in the patient's sample. We searched for pathogenic mtDNA variants as well as autosomal recessive, dominant-acting, or hemizygous X-linked variants but did not identify a likely genetic cause of disease [3].

To complement the SNV and indel analysis, we applied CONIFER to identify large copy number variants (CNVs) in our targeted exome data [4]. CNV analysis revealed a potential $13 \mathrm{~kb}$ heterozygous in-frame deletion of exons 10-13 of HSD17B4 (c.715-1207del; p.239_403del) (Figure 2). Review of patient exome data revealed that the patient also harbored a rare, heterozygous missense variant in HSD17B4 (c.587C > T; p.A196V). The SNV was not present in Exome Variant Server nor 1000 Genomes, altered a residue conserved to bacteria within a predicted NAD-binding domain, and is predicted to be "probably damaging" by PolyPhen2. Familial genotyping confirmed the deletion was inherited from the father, and compounded with a missense mutation inherited from the mother (Figure 2).

Recessive mutations in HSD17B4 have previously been associated with infantile D-bifunctional protein (DBP) deficiency (OMIM \#261515) a severe disorder of peroxisomal fatty acid beta-oxidation that is generally fatal within the first 2 years of life [5]. Recessive HSD17B4 mutations were more recently identified as the cause of Perrault syndrome (OMIM \#233400) in two sisters who fulfilled the defining features of the syndrome (ovarian dysgenesis and sensorineural deafness) and who also presented with peripheral neuropathy and ataxia [6]. Due to the phenotypic overlap with the latter cases, the predicted severity of the HSD17B4 mutations, and biochemical

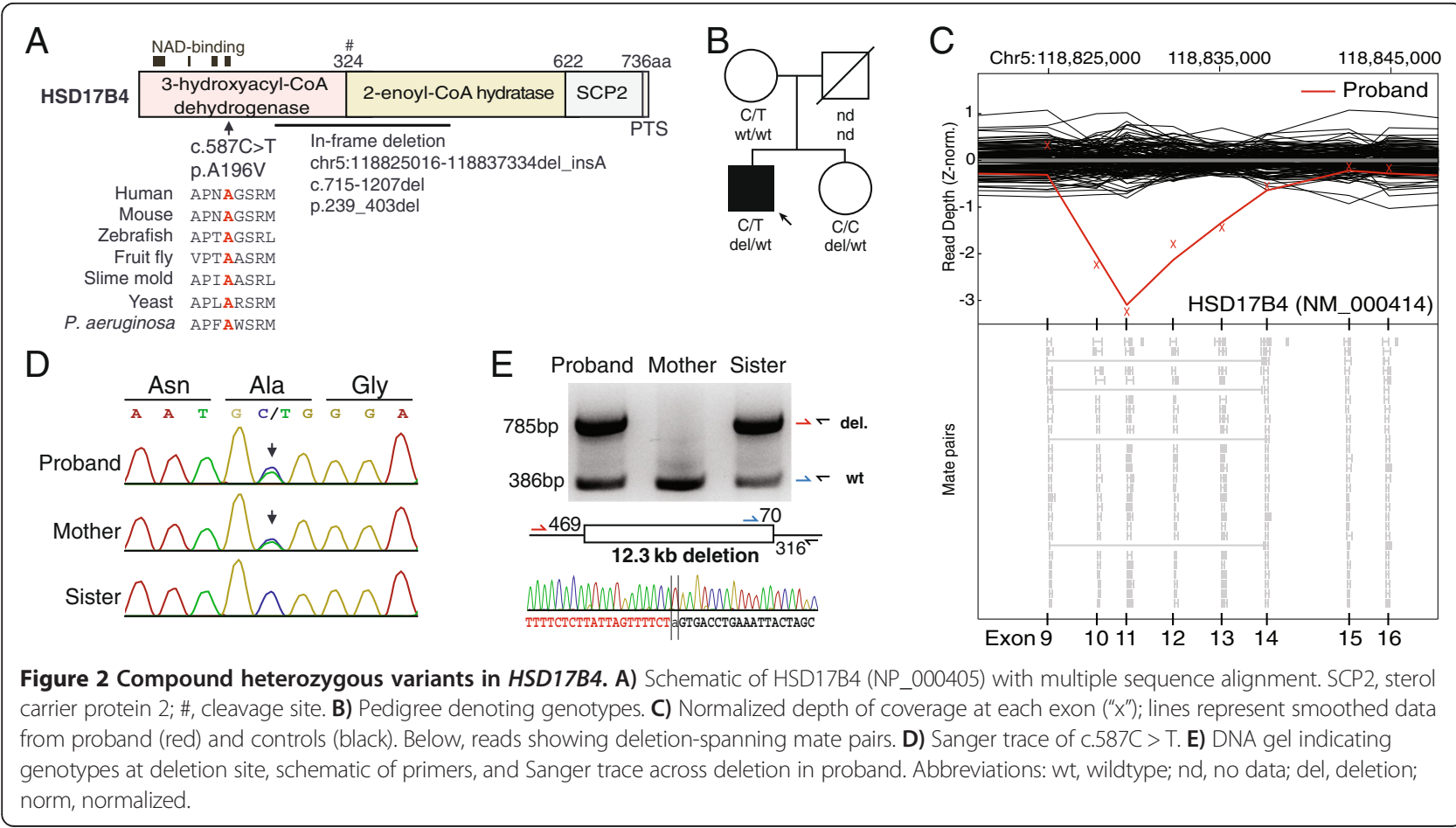


evidence of altered peroxisomal fatty acid metabolism, we reached a diagnosis of HSD17B4 deficiency in our patient.

\section{Discussion and conclusions}

HSD17B4, also known as D-bifunctional protein (DBP), is a peroxisomal enzyme that catalyzes multiple steps of beta-oxidation of very long chain fatty acids (VLCFA). While named for its homology to a steroid-converting enzyme, the protein's role in steroid hormone metabolism is unclear [7]. The protein consists of three domains: an $\mathrm{N}$-terminal dehydrogenase domain, a hydratase domain, and a sterol carrier protein (SCP) domain. The three amino acids at the C-terminus ("AKL") constitute the peroxisomal targeting signal (PTS). After peroxisomal import, the $79-\mathrm{kDa}$ full-length protein is proteolytically cleaved to yield a $35-\mathrm{kDa}$ dehydrogenase subunit and a $45-\mathrm{kDa}$ hydratase subunit containing the hydratase and SCP domains [8].

Recessive mutations in HSD17B4 are known to cause DBP-deficiency, an early-onset neurological disorder characterized by neonatal hypotonia, seizures, visual impairment, and psychomotor retardation [5]. Patients with the disorder generally die in infancy, although a small number survive into their teens [9]. Like our patient, individuals with DBP deficiency often show an elevated ratio of pristanic to phytanic acid in plasma, reflective of dysfunctional beta-oxidation in the peroxisome [10].

DBP-deficiency has been classified into subtypes based on the affected enzymatic activities of HSD17B4. Type I patients have deficiencies of both the hydratase and dehydrogenase subunits whereas types II and III have isolated hydratase or dehydrogenase deficiency, respectively. Recently, a Type IV category was proposed to describe mildly affected patients with compound heterozygous mutations affecting both subunits [11]. Our case may be classified as type IV due to the mutations affecting both subunits and the phenotypic similarity between our patient and two teenage brothers categorized as type IV, including the presence of cerebellar ataxia, polyneuropathy, pes cavus, and hearing loss [11].

Recently, recessive mutations in HSD17B4 have been identified in two sisters as a cause of Perrault syndrome (OMIM \#233400). Perrault syndrome was first defined in 1951 as ovarian dysgenesis and sensorineural hearing loss in females [12]. Brothers of Perrault syndrome females have been reported with hearing loss but are reportedly fertile [13]. Perrault syndrome is genetically heterogeneous and recessive mutations in three additional genes have been implicated to date, including HARS2, LARS2, and CLPP, which respectively encode the mitochondrial histidyl- and leucyl-tRNA synthetases and a mitochondrial ATP-dependent protease [14-17].

The genotype and phenotype of our patient resemble that of the two sisters recently diagnosed with Perrault syndrome [6]. All three cases harbored compound heterozygous $H S D 17 B 4$ mutations affecting the dehydrogenase and hydratase subunits. Both our patient and the older of the two sisters presented with ataxia, demyelinating polyneuropathy, pes cavus, and hearing loss, with marked cerebellar atrophy on MRI. Although levels of VLCFA levels were reportedly normal in the older sister [18], our patient had alterations compatible with DBP deficiency. While the previously reported sisters [6] presented with ovarian dysgenesis, an essential characteristic of Perrault syndrome, our male patient has azoospermia with normal secondary sexual characteristics. Our case raises the hypothesis that azoospermia can be a feature of HSD17B4 deficiency in males, consistent with the finding that HSD17B4 knockout mice exhibit malespecific sterility with testicular lipid accumulation [19].

The mechanisms linking HSD17B4 deficiency and azoospermia remain unclear. Our patient had low testosterone levels, combined with an elevated FSH, suggesting primary testicular failure. HSD17B4 was initially thought to be a steroid-converting enzyme due to its sequence homology, and the enzyme has been shown to display multifunctional properties, including both fatty acid and estradiol oxidation $[7,20]$. However, in vivo studies and computational evidence have suggested that its primary role is likely in fatty-acid metabolism, while steroid conversion is only a secondary and possibly minor activity in vivo [21]. Evidence in mice suggests that HSD17B4 may play an important role in lipid homeostasis in the testes, specifically in Sertoli cells [19]. Further investigation is required to determine how HSD17B4 deficiency may lead to male infertility and low testosterone in humans.

The current case underscores clinical and biochemical overlap between mitochondrial and peroxisomal disorders. Our patient's clinical presentation raised suspicion of mitochondrial disease, leading to a skeletal muscle biopsy that demonstrated mild respiratory chain deficiency. Yet the genetic lesion lies within HSD17B4, a protein classically annotated as being peroxisomal based on detailed localization studies [7]. Interestingly, HSD17B4 is also found within MitoCarta, a large-scale inventory of the mitochondrial proteome [22], suggesting that the protein may be dual localized. The other three genes associated with Perrault syndrome (HARS2, LARS2, CLPP) are also present in MitoCarta, were targeted for sequencing, and no rare, protein-modifying variants were present in the patient. Future studies will be required to determine whether HSD17B4 can indeed be dual-localized to mitochondria and peroxisomes. If so, HSD17B4 would be added to a small but growing list of disease gene products that can be dual localized to these two compartments (e.g. AGXT, MPV17) [23-24]. An alternative explanation may be that defective peroxisomal fatty acid catabolism can lead to secondary mitochondrial 
dysfunction [25], indicating biochemical crosstalk across the two organelles.

\section{Consent}

Study protocols were approved by the Partners Human Research Committee. Written informed consent was obtained for publication of this case report and any accompanying images.

\section{Additional file}

Additional file 1: Supplementary materials including experimental methods, clinical information, and a table of biochemical assay results.

\section{Abbreviations}

mtDNA: Mitochondrial DNA; MRI: Magnetic resonance imaging;

DBP: D-bifunctional protein; OMIM: Online Mendelian inheritance in man; CNV: Copy number variant; PTS: Peroxisomal targeting signal; VLCFA: Verylong-chain fatty acid.

\section{Competing interests}

The authors declare that they have no competing interests.

\section{Authors' contributions}

JDS looked after the patient. DSL, SGH, and SEC performed sequence analysis. NGS, KBS aided in data analysis. JDS, VKM supervised data analysis and interpretation. DSL, SGH, JDS, and VKM wrote the report. All authors contributed to revising the manuscript and approved the final version.

\section{Authors' information}

Jeremy D Schmahmann and Vamsi K Mootha contributed equally to this work as co-senior authors.

\section{Acknowledgements}

We thank S. Vafai, D. McGuone, M. Frosch for discussion and J. Macmore for research assistance. This work was supported by NSF Graduate Research Fellowship (DSL), DOD National Defense Science and Engineering Graduate Fellowship (SGH), grant RC2HG005556 and R01GM97136 from the NGHRI/ $\mathrm{NIH}(\mathrm{VKM})$, the Marriott Mitochondrial Disorders Clinical Research Fund (VKM), and the Birmingham and MINDlink Foundations (JDS).

\section{Author details}

${ }^{1}$ Howard Hughes Medical Institute and Department of Molecular Biology, Massachusetts General Hospital, Boston, MA 02114, USA. ${ }^{2}$ Center for Human Genetic Research, Massachusetts General Hospital, Boston, MA 02114, USA. ${ }^{3}$ Department of Systems Biology, Harvard Medical School, Boston, MA 02115, USA. ${ }^{4}$ Broad Institute of Harvard and MIT, Cambridge, MA 02141, USA ${ }^{5}$ Department of Neurology, Massachusetts General Hospital \& Harvard Medical School, Boston, MA 02114, USA. ${ }^{6}$ Ataxia Unit, Cognitive Behavioral Neurology Unit, Laboratory for Neuroanatomy and Cerebellar Neurobiology, Department of Neurology, Massachusetts General Hospital \& Harvard Medical School, Boston, MA 02114, USA. ${ }^{7}$ Department of Medicine, Massachusetts General Hospital, Boston, MA 02114, USA.

Received: 6 November 2013 Accepted: 25 February 2014 Published: 6 March 2014

\section{References}

1. Zeviani $M$, Simonati $A$, Bindoff $L A$ : Ataxia in mitochondrial disorders. Handb Clin Neurol 2012, 103:359-372.

2. Chinnery PF: Mitochondrial Disorders Overview. In GeneReviews. Edited by Pagon RA, Bird TD, Dolan CR, Stephens K, Adam MP. Seattle (WA): University of Washington, Seattle; 1993.

3. Lieber DS, Calvo SE, Shanahan K, Slate NG, Liu S, Hershman SG, Gold NB, Chapman BA, Thorburn DR, Berry GT, Schmahmann JD, Borowsky ML,
Mueller DM, Sims KB, Mootha VK: Targeted exome sequencing of suspected mitochondrial disorders. Neurology 2013, 80(19):1762-1770.

4. Krumm N, Sudmant PH, Ko A, O'Roak BJ, Malig M, Coe BP, Quinlan AR, Nickerson DA, Eichler EE: Copy number variation detection and genotyping from exome sequence data. Genome Res 2012, 22(8):1525-1532.

5. Ferdinandusse S, Denis S, Mooyer PA, Dekker C, Duran M, Soorani-Lunsing RJ, Boltshauser E, Macaya A, Gartner J, Majoie CB, Barth PG, Wanders RJ, Poll-The BT: Clinical and biochemical spectrum of D-bifunctional protein deficiency. Ann Neurol 2006, 59(1):92-104.

6. Pierce SB, Walsh T, Chisholm KM, Lee MK, Thornton AM, Fiumara A, Opitz JM, Levy-Lahad E, Klevit RE, King MC: Mutations in the DBP-deficiency protein HSD17B4 cause ovarian dysgenesis, hearing loss, and ataxia of Perrault Syndrome. Am J Hum Genet 2010, 87(2):282-288.

7. Adamski J, Normand T, Leenders F, Monte D, Begue A, Stehelin D, Jungblut PW, de Launoit Y: Molecular cloning of a novel widely expressed human $80 \mathrm{kDa}$ 17 beta-hydroxysteroid dehydrogenase IV. Biochem J 1995, 311(Pt 2):437-443.

8. Leenders F, Husen B, Thole HH, Adamski J: The sequence of porcine 80 $\mathrm{kDa} 17$ beta-estradiol dehydrogenase reveals similarities to the short chain alcohol dehydrogenase family, to actin binding motifs and to sterol carrier protein 2. Mol Cell Endocrinol 1994, 104(2):127-131.

9. Ferdinandusse S, Ylianttila MS, Gloerich J, Koski MK, Oostheim W, Waterham HR, Hiltunen JK, Wanders RJ, Glumoff T: Mutational spectrum of D-bifunctional protein deficiency and structure-based genotype-phenotype analysis. Am J Hum Genet 2006, 78(1):112-124.

10. Paton BC, Sharp PC, Crane DI, Poulos A: Oxidation of pristanic acid in fibroblasts and its application to the diagnosis of peroxisomal beta-oxidation defects. J Clin Invest 1996, 97(3):681-688.

11. McMillan HJ, Worthylake T, Schwartzentruber J, Gottlieb CC, Lawrence SE, Mackenzie A, Beaulieu CL, Mooyer PA, Forge Canada C, Wanders RJ, Majewski J, Bulman DE, Geraghty MT, Ferdinandusse S, Boycott KM: Specific combination of compound heterozygous mutations in 17beta-hydroxysteroid dehydrogenase type 4 (HSD17B4) defines a new subtype of D-bifunctional protein deficiency. Orphanet J Rare Dis 2012 7(1):90.

12. Perrault M, Klotz B, Housset E: Two cases of Turner syndrome with deaf-mutism in two sisters. Bull Mem Soc Med Hop Paris 1951, 67(3-4):79-84.

13. Christakos AC, Simpson JL, Younger JB, Christian CD: Gonadal dysgenesis as an autosomal recessive condition. Am J Obstet Gynecol 1969, 104(7):1027-1030.

14. Jenkinson EM, Clayton-Smith J, Mehta S, Bennett C, Reardon W, Green A, Pearce SH, De Michele G, Conway GS, Cilliers D, Moreton N, Davis JR, Trump D, Newman WG: Perrault syndrome: further evidence for genetic heterogeneity. J Neurol 2012, 259(5):974-976.

15. Jenkinson EM, Rehman AU, Walsh T, Clayton-Smith J, Lee K, Morell RJ, Drummond MC, Khan SN, Naeem MA, Rauf B, Billington N, Schultz JM, Urquhart JE, Lee MK, Berry A, Hanley NA, Mehta S, Cilliers D, Clayton PE, Kingston H, Smith MJ, Warner TT, Black GC, Trump D, Davis JR, Ahmad W, Leal SM, Riazuddin S, King MC, Friedman TB, et al: Perrault syndrome is caused by recessive mutations in CLPP, encoding a mitochondrial ATP-dependent chambered protease. Am J Hum Genet 2013, 92(4):605-613.

16. Pierce SB, Chisholm KM, Lynch ED, Lee MK, Walsh T, Opitz JM, Li W, Klevit RE, King MC: Mutations in mitochondrial histidyl tRNA synthetase HARS2 cause ovarian dysgenesis and sensorineural hearing loss of Perrault syndrome. Proc Natl Acad Sci USA 2011, 108(16):6543-6548.

17. Pierce SB, Gersak K, Michaelson-Cohen R, Walsh T, Lee MK, Malach D, Klevit RE, King MC, Levy-Lahad E: Mutations in LARS2, encoding mitochondrial leucyl-tRNA synthetase, lead to premature ovarian failure and hearing loss in perrault syndrome. Am J Hum Genet 2013.

18. Fiumara A, Sorge G, Toscano A, Parano E, Pavone L, Opitz JM: Perrault syndrome: evidence for progressive nervous system involvement. Am J Med Genet A 2004, 128A(3):246-249.

19. Huyghe S, Schmalbruch H, De Gendt K, Verhoeven G, Guillou F, Van Veldhoven PP, Baes M: Peroxisomal multifunctional protein 2 is essential for lipid homeostasis in Sertoli cells and male fertility in mice. Endocrinology 2006, 147(5):2228-2236.

20. Rasiah KK, Gardiner-Garden M, Padilla EJ, Moller G, Kench JG, Alles MC, Eggleton SA, Stricker PD, Adamski J, Sutherland RL, Henshall SM, Hayes VM: HSD17B4 overexpression, an independent biomarker of poor patient outcome in prostate cancer. Mol Cell Endocrinol 2009, 301(1-2):89-96. 
21. Breitling R, Marijanovic Z, Perovic D, Adamski J: Evolution of 17beta-HSD type 4, a multifunctional protein of beta-oxidation. Mol Cell Endocrinol 2001, 171(1-2):205-210.

22. Pagliarini DJ, Calvo SE, Chang B, Sheth SA, Vafai SB, Ong SE, Walford GA, Sugiana C, Boneh A, Chen WK, Hill DE, Vidal M, Evans JG, Thorburn DR, Carr SA, Mootha VK: A mitochondrial protein compendium elucidates complex I disease biology. Cell 2008, 134(1):112-123.

23. Salido EC, Li XM, Lu Y, Wang X, Santana A, Roy-Chowdhury N, Torres A, Shapiro LJ, Roy-Chowdhury J: Alanine-glyoxylate aminotransferasedeficient mice, a model for primary hyperoxaluria that responds to adenoviral gene transfer. Proc Natl Acad Sci USA 2006, 103(48):18249-18254.

24. Spinazzola A, Viscomi C, Fernandez-Vizarra E, Carrara F, D'Adamo P, Calvo S, Marsano RM, Donnini C, Weiher H, Strisciuglio P, Parini R, Sarzi E, Chan A, DiMauro S, Rotig A, Gasparini P, Ferrero I, Mootha VK, Tiranti V, Zeviani M: MPV17 encodes an inner mitochondrial membrane protein and is mutated in infantile hepatic mitochondrial DNA depletion. Nat Genet 2006, 38(5):570-575

25. Lopez-Erauskin J, Galino J, Ruiz M, Cuezva JM, Fabregat I, Cacabelos D, Boada J, Martinez J, Ferrer I, Pamplona R, Villarroya F, Portero-Otin M, Fourcade S, Pujol A: Impaired mitochondrial oxidative phosphorylation in the peroxisomal disease X-linked adrenoleukodystrophy. Hum Mol Genet 2013, 22(16):3296-3305.

doi:10.1186/1471-2350-15-30

Cite this article as: Lieber et al:: Next generation sequencing with copy number variant detection expands the phenotypic spectrum of HSD17B4-deficiency. BMC Medical Genetics 2014 15:30.

\section{Submit your next manuscript to BioMed Central and take full advantage of:}

- Convenient online submission

- Thorough peer review

- No space constraints or color figure charges

- Immediate publication on acceptance

- Inclusion in PubMed, CAS, Scopus and Google Scholar

- Research which is freely available for redistribution 